\title{
Viewers' Interpretation of the Myth (A Semiotic Analysis of Natural Extract Fiber Brand X Commercials Aired on Televisions From 2009 to 2011)
}

\author{
Muhamad Gibraltar S. Sos., M. Si \\ Department of Communication; School of Communication, International Relations, and Law; President University, Bekasi, Indonesia
}

\section{Email address:}

gibraltarmuhammad@gmail.com (Muhamad G. S. Sos.), gibraltarcommunication51@gmail.com (Muhamad G. S. Sos.)

\section{To cite this article:}

Muhamad Gibraltar. Viewers' Interpretation of the Myth (A Semiotic Analysis of Natural Extract Fiber Brand X Commercials Aired on Televisions From 2009 to 2011). Humanities and Social Sciences. Vol. 2, No. 4, 2014, pp. 96-107. doi: 10.11648/j.hss.20140204.12

\begin{abstract}
The purpose of the present study was to look at the extent to which the viewers interpreted the myths constructed from two natural extract fibers Brand X commercials aired on televisions from 2009 to 2011 . And, it is the perfection from my thesis at postgraduate program of Communication Studies, University of Indonesia. The selection of the two commercials as the units of analysis was based on two conflicting reasons. On the one hand, the manufacturer claimed that the products were good for consumers' digestive health; on the other hand, the opponents considered the products as harmful to digestive health. For the purpose of analysis, the theoretical framework of the study combined Roland Barthes' semiotics with other thoughts such as from Arthur Asa Berger, Barker, Darmaprawira, and Mas Dian on the first level of analysis in order to explore the myths. Subsequently, the analysis used Susanne Langer's discursive symbolism in order to examine how the myths were interpreted by the viewers. At the methodological level, there was a mix or triangulation, both between literature review and in-depth interview, and between illustrative method and negative sentence method. Through the "two-level" analysis, two kinds of myths were explored from the two different commercials. The first was that natural extract fibers Brand $\mathrm{X}$ was better than natural fruits and vegetables in preventing from hemorrhoids. However, when this myth was tested using in-depth interviews, it was interpreted negatively or not trusted by viewers at all. The second was that the second (ordinary and herbal) product was better than natural fruits and vegetables in smoothening defecation, in which when this myth was tested using in-depth interviews; it was trusted by viewers due to the presence of hilarious and comic Ulfa Dwiyanti as the model of the commercial.
\end{abstract}

Keywords: Signifier, Signified, Myths, Signs, Symbols, Denotation, Connotation, Interpretation, Sociology, Representation.

\section{Introduction}

In analyzing contemporary commercials, some modifications should be made, whether in the theoretical and methodological level, given that the case studies are diverse. In fact, commercials are capable of influencing the public, in particular the interpretation of the viewers watching the commercials.

This research is the extension and perfection from my thesis in at Postgraduate Program in Communication Studies, University of Indonesia in 2012, whose title is: Interpretasi Pemirsa Terhadap Penanda dan Petanda: Analisis Semiotika Iklan Sari Serat Alami Merek X Di Televisi Antara Tahun 2009-2011. In fact, my thesis does not explain the myths, and the viewers' interpretation for them specifically. (Gibraltar, 2012: 203-204)

This was the case with American society in 2003. In her study, Elizabeth C. Hirschman concluded that dialectics occurred among American society, particularly among individuals, which manifested in tensions between masculinity and femininity, the whites and non-whites, racial identities, etc. (Hirschman, 2001: 21).

There were also several studies showing how signs and symbols in advertising could give birth to communities supporting certain products, such as in the case of Nike in the United States (Grow, 2006).

In other cases, meanings were frequently not conveyed completely to viewers as what was intended by its creators, one of which was caused by the barriers of the symbols used, such as a $20 \%$ loss of meanings and associations in 
Guinness beer ad modeled by Japanese celebrities when advertised in other countries (Harvey \& Evans, 2001: 186)

All of this is related to the interpretation of viewers watching the ads, which represents an important factor.

This was the case when examining natural extract fibers Brand X commercials aired on televisions from 2009 to 2011.Two of those commercials were chosen as the units of analysis: Ulfa Dwiyanti version and hemorrhoid version. In fact, this product gained numerous awards, ranging from "The Best in Achieving Total Customer Satisfaction "for two consecutive years of 2002 and 2003, the "Original Brands Indonesia 2010" for two consecutive years of 2002 and 2003, to the "Top Brands Awards 2010" from Marketing Magazine. Many people assumed that the way this product was advertised was able to show an impression of "trusted", causing consumers interested in buying it (Palupi \& Pambudi, 2005: 157).

Instead, dr, Ir. Donny Hosea MBA considers this product might harm consumers' health due to the fact that it was able to cause a hardening of the intestinal wall, colon cancer, and should be accompanied with 8 glasses of water after consumption (Gibraltar, 2012: 4-5).

An attempt to analyze viewers' interpretation is almost similar to Richard Tressider's study of consumers' interpretation of the semiotics of food products. It is explained that individuals negotiate social and cultural values represented in signs and images (Tressider, 2010: 483)

Lastly, the study whose title is "Image, Sign, Identity: Jean Marie Floch and Visual Semiotics". Moreover, this research tells about the method and concept of the new semiotic, which have been developed by Floch himself. Starting from Figurative Semiotic, Plastic Semiotic, and Visual Identities, in analyzing of two volumes of monographs. (Floch, 2012).

To conclude, all five studies are not discussed about the viewer's interpretation of Myths from commercials. Therefore, hopefully this research can fill that gap.

In general, this paper addresses two questions: (1) what are myths contained in both commercials? (2) How do viewers interpret both commercials when watching them?

Therefore, main problems of this paper are: (1) digging myths contained in both commercials (first level of analysis); and (2) examining viewers'interpretation of both commercials when watching them.

With regard to the analytical tool for addressing both questions, this paper attempts to present an "up-grading" of Roland Barthes' thoughts in the realm of communication science. Usually, Roland Barthes' "two-level" semiotics is initially used as a "methodological tool", and then upgraded again to its previous level, the theoretical level (Gibraltar, 2012: 204-205).

Upgrading from theory to methodology, and vice versa, can be carried out in accordance with the needs of the study. In fact, Roland Barthes was a sociologist; thus, his thought scan be equated with Talcott Parson's social systems theory, Emile Durkheim's social facts, and Karl Marx's conflicts. However, the level of analysis is different. In a nutshell, semiotics can be interpreted as \$ociology of signs, symbols, and representations (Barthes, 2010).; so, semiotics is itself also sociology, not merely a methodological tool for collecting data from a text.

A "simulacra" (semiotic interpretation of a text on paper) should be matched to what is interpreted by viewers, instead of being separate from actual realities in the society (Gibraltar, 2012: 5). To make it happen, it would be appropriate to combine Roland Barthes' semiotics with other thoughts in order to create a directional and comprehensive "on paper" analysis. In short, Roland Barthes' thoughts can be used as a theoretical "container" to accommodate other thoughts such as Arthur Asa Berger's concretization of the signifier and signified, Barker's colors and moods, Mark L. Knapp's nonverbal communication, Darmaprawira and Mas Dian's color. In the theoretical container, all the frameworks of thought are combined to form an analytical knife (Gibraltar, 2012: 34-35).

Here is a schematic that depicts a blend of various theories and thoughts, starting from the first stage, up to the second one: (Gibraltar, 2012: 34-35).

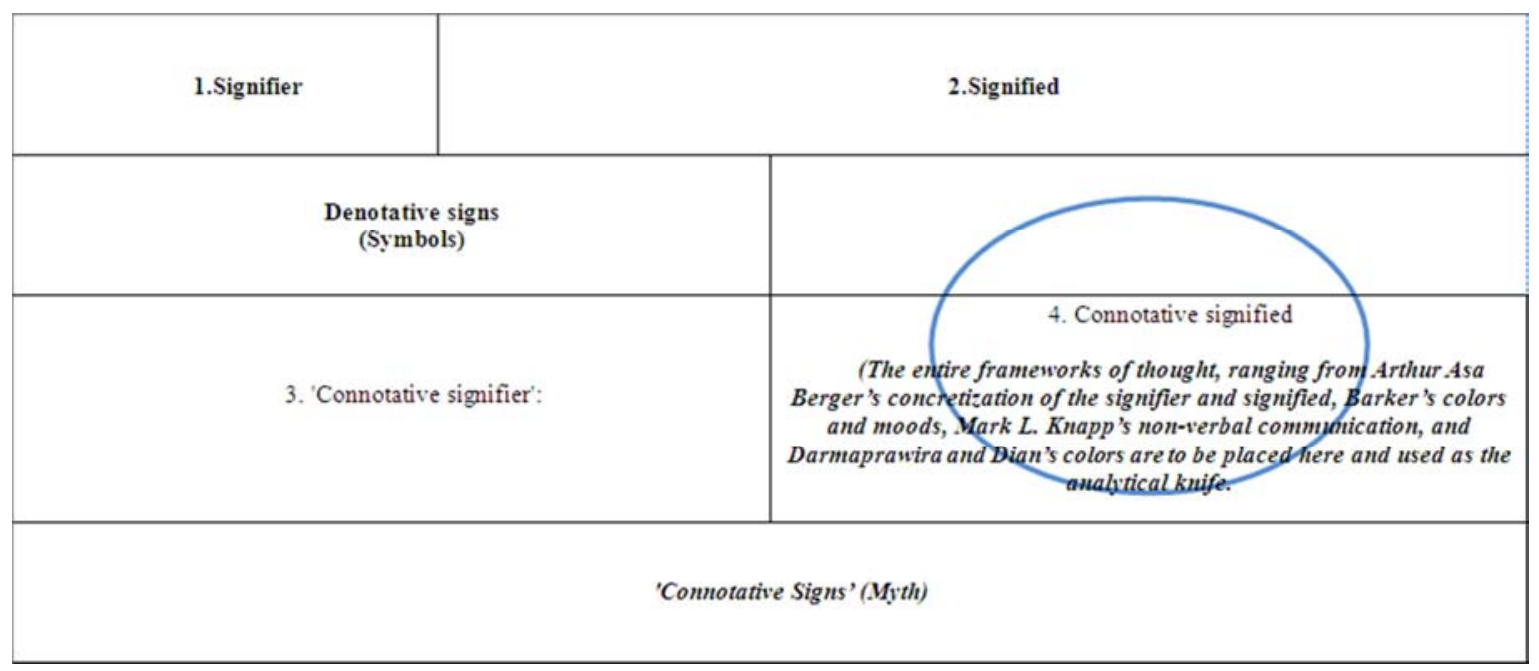

Figure 1.1. A blend of various frameworks of thought (addressing the first research question) 
Various theories complementing Roland Barthes' semiotics are elucidated as follows:

A. Concretization of this reasoning is as expressed by Arthur Asa Berger in Table 1.1 (Sobur, 2009: 174175) as follows:

Table 1.1. Concretizations of Signifier and Signified

\begin{tabular}{ll}
\hline Signifier & Signified \\
\hline 1. Long hair & $\begin{array}{l}\text { Noncompliant with the culture } \\
\text { (Especially for shabby hair) }\end{array}$ \\
2. Neat hair style & Entrepreneurs \\
3. Hair cut too short & Gays or soldiers/both \\
4. Brick brown & Fond of sports, leisure activities \\
5. Pale & Intellectuals (sick people) \\
6. Levi's & Casual clothes, the proletariat \\
7. Designer jeans & Respected, luxurious \\
8. K. Mart's jeans & Workers \\
9. Three sets of formal clothes & Executives, entrepreneurs \\
10. Suitcases & Old-fashioned, traditional \\
11. Diplomatic bags & Typical successful entrepreneurs \\
12. Handbags & European style, Italian descents \\
13. Backpacks & Nomad \\
14. Shopping bags & Farmers \\
15. Sandals & Artists \\
16. Winged & Typical entrepreneurs \\
17. Worker's boots & Workers \\
18. Nomad's boots & Nature lovers, wanderers \\
19. Pilot's glasses & Middle class \\
20. Chain glasses & Strange people \\
21. Dark/black glasses & Typical street, crazy people \\
22. Tie with knot tie & Educated people \\
23. Thick tie & Old-fashioned people \\
24. Rope tie & Villagers, Western people \\
\hline & \\
\hline
\end{tabular}

B. Similarly, Arthur Asa Berger's elucidation of the motion of the camera, shooting, and size of shooting is as follows:

Table 1.2. Size of shooting (Adityawan, 2008: 41)

\begin{tabular}{lll}
\hline $\begin{array}{l}\text { Signifier of } \\
\text { Shooting }\end{array}$ & Definition & Signified \\
\hline Close-Up & Only the face & Intimacy \\
Medium Shot & Nearly the entire body & $\begin{array}{l}\text { Personal relationships } \\
\text { Context, scope, public's } \\
\text { distance }\end{array}$ \\
Long Shot & Setting and characters & Personal relationships \\
\hline
\end{tabular}

Table 1.3. Motion of Camera and Change of Images (Adityawan, 2008: 41)

\begin{tabular}{lll}
\hline $\begin{array}{l}\text { Signifier of } \\
\text { Shooting }\end{array}$ & Definition & Signified \\
\hline Pan Down & $\begin{array}{l}\text { The camera pointing } \\
\text { downwardly }\end{array}$ & Power, authority \\
Pan Up & $\begin{array}{l}\text { The camera pointing } \\
\text { upwardly }\end{array}$ & Weakness, diminution \\
Dolly In & $\begin{array}{l}\text { The camera moving } \\
\text { inwardly }\end{array}$ & Observation, focus \\
\hline
\end{tabular}

\begin{tabular}{|c|c|c|}
\hline Fade In & $\begin{array}{l}\text { The image seen on the } \\
\text { blank screen }\end{array}$ & Beginning \\
\hline Fade Out & $\begin{array}{l}\text { The image on the } \\
\text { screen lost }\end{array}$ & Closure \\
\hline Cut & $\begin{array}{l}\text { Moving from one } \\
\text { image to another }\end{array}$ & Continuity, interesting \\
\hline Wipe & $\begin{array}{l}\text { The image wiped out } \\
\text { from the screen }\end{array}$ & $\begin{array}{l}\text { "Determination" of } \\
\text { conclusion }\end{array}$ \\
\hline
\end{tabular}

Table 1.4. Visual Languages and Importance (Adityawan, 2008: 42)

\begin{tabular}{|c|c|c|}
\hline Sign & Important & Unimportant \\
\hline \multirow{2}{*}{ Size/Scale } & Large & Small \\
\hline & $\begin{array}{l}\text { Bigger than the } \\
\text { surroundings }\end{array}$ & $\begin{array}{l}\text { Smaller than/equal to } \\
\text { the surroundings }\end{array}$ \\
\hline \multirow[t]{4}{*}{ Position } & Center & Edge \\
\hline & Front & Back \\
\hline & Top & Bottom \\
\hline & Upper-Left hand & Lower-Right hand \\
\hline $\begin{array}{l}\text { Angle/Position of } \\
\text { Camera }\end{array}$ & Under the Object & Above the Object \\
\hline Figure/Object Light & Light & Dark \\
\hline Background Light & Light & Dark \\
\hline $\begin{array}{l}\text { Focus/Depth of } \\
\text { Field }\end{array}$ & Clear/Sharp & Unclear/Blurred \\
\hline $\begin{array}{l}\text { Frequency of } \\
\text { Appearance }\end{array}$ & Often Appears & Rarely Appears \\
\hline Accent & $\begin{array}{l}\text { Different from the } \\
\text { surroundings }\end{array}$ & $\begin{array}{l}\text { Same as the } \\
\text { surroundings }\end{array}$ \\
\hline
\end{tabular}

C. With regards to colors, everyone must have favorite colors and usually those colors affect moods. The following is a description of color-associated moods as suggested by Barker (1954) (Sobur, 2009: 174-175)

Table 1.4. Color-Associated Moods

\begin{tabular}{ll}
\hline Mood & Color \\
\hline Exciting, stimulating & Red \\
Safe, Comfortable & Blue \\
Depressed, disturbed, confused & Orange \\
Soft, soothing & Blue \\
Protecting, defending & Red, Brown, Black \\
Very sad, heartbroken, unhappy & Black, Brown \\
Calm, peaceful, serene & Blue, Green \\
Dignified, noble & Purple \\
Fun, carefree, happy & Yellow \\
Challenging, hostile & Red, Orange \\
Powerful, robust, excellent & Black \\
\hline
\end{tabular}

D. Colors are fundamental elements in the visualization of commercials. Colors play an important role in creating meanings from commercials, especially in terms of emotions and feelings. In art, the use of symbolic colors is an event considered important. According to Darmaprawira, some colors that have symbolic values in general, among others, are (Darmaprawira, 2002: 45-49):

Red: Of all the colors, red is the strongest and most 
interesting color; aggressive in nature and symbolizing the primitive. This color is associated with blood, anger, brevity, sex, danger, strength, virility, love, and happiness.

Purplish red: This color has the characteristics of the noble, glorious, rich, proud (arrogant), and impressive.

Purple: This color is characteristic of the cool, negative, backward; almost similar to blue but deeper and more solemn; moody and quitter character. This color symbolizes sorrow; contemplative; sacred; a religious emblem.

Blue: Of cool, passive, quiet, and peaceful character. Goethe considered this color as dazzling, spiritual, monotheistic, and lonely; presently thinking about the past and future. Blue is a perspective color, drawing us to solitude, chill, separation; and creating distance. Blue symbolizes the sanctity of hope and peace.

Green: Symbolizes contemplation, belief (religion) and immortality. It also reveals freshness, rawness, young, immaturity, growth and hope, rebirth and fertility. The negative sides of the green are that it is disliked by the kids; associated with disease, hatred, venom, and jealousy.

Yellow: Symbolizes pleasure, agility, and intellectuality; it also explains the glory of love as well as a deep understanding of the relationships among people.

White: Has positive, stimulating, bright, light, and simple characters; it also symbolizes purity, innocence, honesty, and purity.

Gray: Symbolizes calmness, politeness, and modesty. It also symbolizes intelligence, but has a negative epitome of indecision. Additionally, it symbolizes the neutral mediator of conflicts.

Black: Symbolizes darkness and absence of light; indicating a dark force; the symbol of mystery and color of the night; also, often denoted as color of destruction or mistake. It can also indicate firm, formal attitude; robust structure.

Further, Mas Dian, a Feng Shui consultant, in her book "The Influence of Colors in Feng Shui", published in 2002, argued that colors have characteristic properties that unequivocally affect one's psychic and can provide a variety of inspirations that evoke emotions. He also suggested that the language of colors have different meanings, such as (Dian, 2002: 1-2):

Pink: describing the feminine, soft, tender, beautiful and romantic.

Red: denoting the energetic, mighty, dynamic, active, and hot.

Beige: representing the soft, classic, exclusive, neutral, warm, and sweet.

Orange: describing the merry, popular, hard, bright, hot, and eager.

Light yellow: representing the chirpy, bright, warm, soft, beautiful, and sweet.

Light green: denoting the fresh, ecstatic, cheerful, and growth.

Green: describing the classic, cool, worldly, exclusive, and calm.

Lightblue: symbolizing the calm, clean, quiet, peaceful, gentle, and relaxing.

Blue: describing the classic, strong, confident, calm, and professional.

White: describing the pure, clean, calm, sacred, classical, sheen, and grief.

Black: symbolizing the classical, elegant, mystical, powerful, hard, sexy, and dramatic.

Silver: describing exclusive or expensive, classic, elegant and cool impressions.

Gold: symbolizing energetic, mighty, dynamic, active, and hot impressions.

Furthermore, signs described above would theoretically turn into symbols if it involves viewers' interpretation. The present study attempted to incorporate Susanne Langer's "discursive symbolism", which would explain rationalization of signs that would transform into symbols (Gibraltar, 2012: 36). Further, Susanne Langer argued "Symbols are not the proxy of their objects, but are vehicles for conception of objects" (in Littlejohn \& Foss, 2002: 63).

Interpretation can be defined as the the process of looking about for kinds of things to which a certain form belongs (Langer, 1967: 37). Moreover, by doing interpretation, we can interpret empty forms we have quite abstractly constructed (Langer, 1967: 38).

So that in the second stage, Susanne Langer's discursive symbolism would be used in order to address symbols since signs contained in both natural extract fibers Brand $\mathrm{X}$ commercials had been watched by viewers, giving rise to interpretations in the minds of individual viewer.

The following is an illustration of the second level of analysis (Gibraltar: 2012: 45) (addressing the second research question).
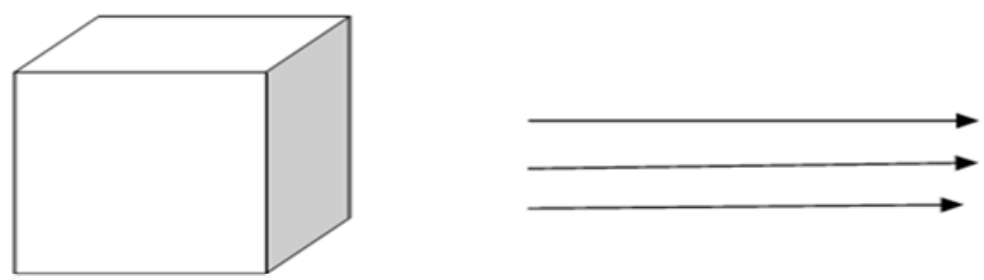

Televisions aired the three Sari Serat Alami Brand X commercials

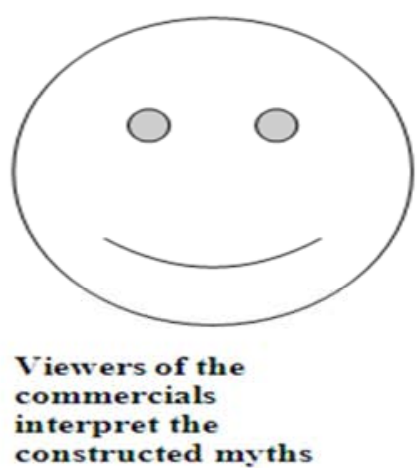


In conclusion, Roland Barthes' semiotics can be raised from methodology to theory or lowered from theory to methodology in accordance with the needs of the unit of analysis, which are then combined with other thoughts of Arthur Asa Berger, Barker, Darmaprawira, and Mas Dian in the first level of analysis (semiotics). Then, analysis proceeds with looking at how the myth is interpreted by viewers watching the commercials by using Susanne Langer's discursive symbolism.

\section{Research Methods}

This present study use and interpretive paradigm by combining two kinds of research methods: literature review and in-depth Interview, which was a semi-structured interview. Additionally, illustrative method as the method of data analysis, seen as empty glasses to be filled with water, was triangulated with the negative sentence method as a comparison or triangulation in order to obtain qualitative explanation as a whole (Gibraltar, 2012: 52-63).

A qualitative researcher might favor a semistructured interview over an unstructured one for two reasons. First, the researcher may have narrowed down his or her focus to the point of wanting information from an informant only on those specific questions. Second, the researcher might prefer a semistructure protocol is if he or she wants to make explicit comparisons between informants. (Baxter \& Babbie, 2004: 330)

This study took place in two settings, given that natural extract fibers Brand $\mathrm{X}$ was a product affordable to various segments, starting from the lower-middle class to uppermiddle class. The first setting was Kelurahan Kukusan, Kecamatan Beji of Depok in order to obtain representative (male and female) informants; the second was Perumahan Gema Pesona Depok in order to obtain one representative male and female informant. The snowball sampling method was used (Gibraltar, 2012: 52-53).

Then, one informant would be selected by using the "theoretical sampling" method, in which the herbalist doctor was selected. In short, the doctor held an "antiestablishment" view that later could provide a comprehensive explanation of natural extract fibers Brand $\mathrm{X}$ and Herbal natural extract fibers Brand $\mathrm{X}$, without covering up the flaws of the products with a less precise information, particularly that related to the consumers' health (Gibraltar, 2012: 54-55).

Correlating with the seriousness / relevance, there must be the "Goodness Criteria"'(Seale et all, 2007: 377). The researcher took 5 aspects to guarantee the quality of this research. They are (Gibraltar, 2012: page 51):

A. Completeness of Descriptions: This research explained signs interpretation at both commercials comprehensively. Moreover, it was not only using The Roland Barthes semiotic analysis, but also combining with the other theoretical frameworks such as: Barker, Mark L. Knapp, Arthur Asa Berger, Darmaprawira, and Mas Dian. It is because it is the unique study, not only involving content, expression, and representation but also color, mimic, gesture, face, and voice.

B. Authenticity: The researcher showed the verbatim excerpt completely, gathered from five informants from different economic and occupational backgrounds.

C. Ecological Validity and Credibility: The Discursive Symbolism of Susanne Langer played as the "bridge" between the sign and symbol, in order to portray the real condition of the society.

D. Plauseability : The researcher used the Roland Barthes semiotic theory as the theoretical container in order to keep other theories "on track".

\section{Results and Discussion}

\subsection{Four Constructions of Signs and One Myth as a Final Product of Each Commercial}

The findings of this study are of significance in changing communication academics' and practitioners'perspectives in addressing advertising issues, given that a semiotic analysis that is in fact "on paper" is far from sufficient to bridge what is written on paper with society's actual interpretation when watching the commercials. According to Roland Barthes'semiotics, the myths formed were not necessarily interpreted positively by the society. This is the case with construction of signs. When transformed into symbols, signs are not necessarily interpreted positively by society. In fact, viewers reject them.

The present study began with discussion based on Roland Barthes' semiotic analysis, which would produce myths as the final products.

In the episode of hemorrhoid version commercial, at least 4 constructions of sign were formed, and one combination of other thoughts from communication sciences. Here is the explanation (Gibraltar, 2012: 101):

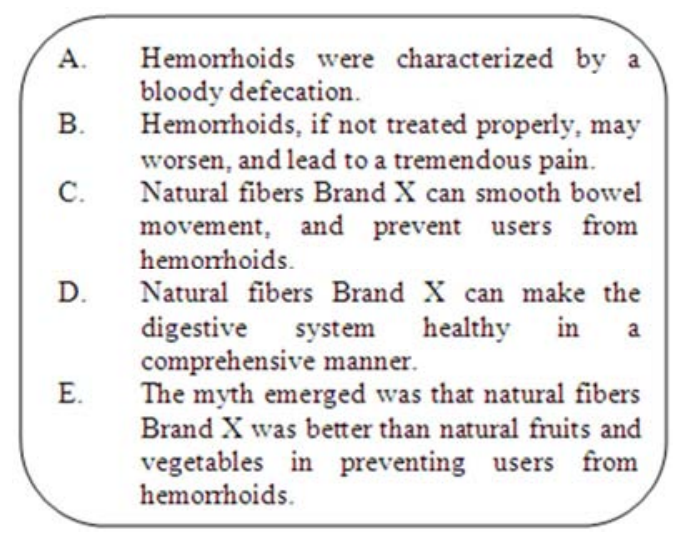

The first construction of sign (hemorrhoids are characterized by bloody defecation) was described clearly by Figures 2, 3 and 4. On figure 2, the core of the discussion was the sentence uttered by the woman dressed in orange: "I had bloody bowel movements". The whispering hand gestures showed confidentiality. The 
orange shirt indicated how depressed and disrupted the woman dressed in Orange was against her illness. Her long hairs did not conform to the culture. In contrast, the shorthaired woman dressed in pink acted as a close friend (portrayed in a "close up" by the camera, indicating an intimacy) (Gibraltar, 2012: 70-71).

On Figure 3, the woman dressed in pink with shoulderlength hairs, a serious facial expression, the face directed forward, eyes and mouth slightly leaning forward, as well as the close-up camera motion (indicating intimacy with the interlocutor, like a close friend), expressed her opinion: "It's a hemorrhoid", which was the core of the first construction of sign (Gibraltar, 2012: 74-75).

The pink blouse indicated female tenderness (portrayed as a beautiful woman) against the illness suffered by her friend (Gibraltar, 2012: 77).

Construction of this sign was further made clear by the Figure 4. The woman's long flowing hairs indicated that she had a problem (did not conform to the culture) (Gibraltar, 2012: 82). Then, along with "close-up" (indicating what the women said was important informationand an intimacy with the interlocutor) and "pan-down" (indicating that the woman had the authority to express her opinion because of her illness) camera motions, the woman dressed in orange said, "It was often hard, now it's bleeding", which was actually the core message in this scene of the commercial. Her facial expression showed a deep concern about her illness. Her orange blouse indicated that this woman was stressful, distracted, or depressed due to the illness (Gibraltar, 2012: 79-80).

Here are the pictures to display the second, third, and fourth from advertising natural extract fibers Brand $\mathrm{X}$ version of hemorrhoids:

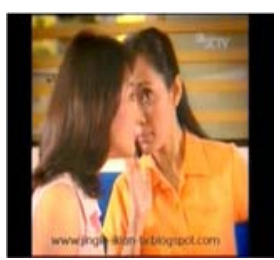

Figure 2.

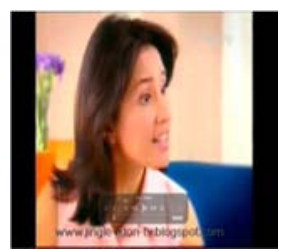

Figure 3.

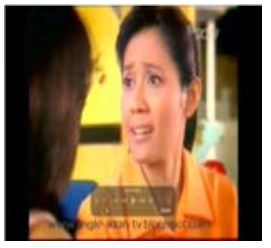

Figure 4.
Construction of the second sign (hemorrhoids, if not treated properly, may worsen, and lead to a tremendous pain) was described clearly by Figure 5 . The long hairs showed that the women complained of pain (seen from her facial expression). The medium shot showed a close personal relationship between the two women, like two good friends (Gibraltar, 2012: 82-83).

Black and white colors indicated the absence of light or darkness, indicating that there was a problem with the digestion of the long-haired woman. White color indicated innocence, purity and honesty, in the sense that the scene was actually happening, though it was indeed a mere fiction. But the main message was the sound suddenly came out: "Beware of hemorrhoids, the longer the more severe" (Gibraltar, 2012: 83).

This second construction of sign was reinforced by Figure 6. The pink color on the woman showed femininity, gentleness, and tenderness in understanding the health problem of her friend. Medium shot of both women showed the personal relationships between them, as two close friends. However, what were central in the scene were the words of the woman dressed in pink: "So, do not have hard bowel movements, the longer the more critical" (Gibraltar, 2012: 86).

Here is Figure 5 and 6:

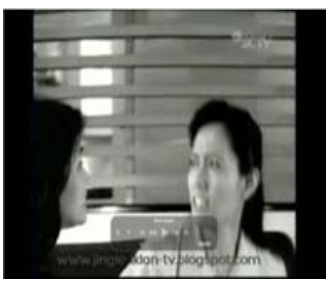

Figure 5.

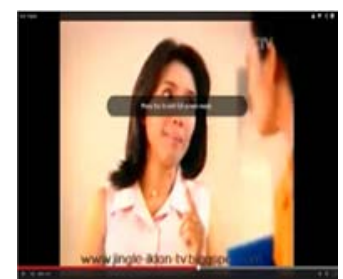

Figure 6.

The third construction (Natural extract fibers Brand X can smooth bowel movement, and prevent users from hemorrhoids) actually has already started to appear on Figure 7A. The utterance "What should I do" was coupled with the woman dressed in pink touching the thigh of the woman dressed in orange, indicating a hidden solution that would appear on the next scenes. The "dolly in" camera motion was directing the viewers' eyes to focus or observe the glass on the table (as the solution) (Gibraltar, 2012: 89).

This construction was reinforced by Figure 7B, especially the utterance of the woman dressed in pink who says: "I drink natural extract fibers Brand X twice a day; there is no hard bowel movement, and hemorrhoids are resolved". Orange color on the long-haired woman 
indicated her distress and depression due to her health problem. The short-haired woman dressed in pink understood her friend's problem. The text with white background (denoting the honest, innocent, and pure) "drink twice a day" indicated that the product was lightweight, easy to use, and honest since it did not contain harmful substances, and pure or sterile. The woman's hand movements showed how this productcould be used effectively to cope with hemorrhoids (Gibraltar, 2012: 9495).

The following are Figures 7A and 7B:

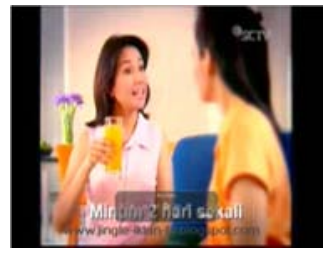

Figure $7 A$.

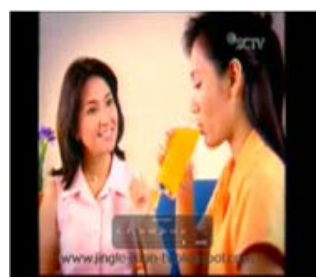

Figure $7 B$.

The fourth social construction (Natural extract fibers Brand $\mathrm{X}$ can make the digestive system healthy in a comprehensive manner) was described by Figure 8. The "close-up" camera motion suggested intimacy or entanglement between the sachet and the glass containing a yellow solution, which showed how to consume it and as the solution to hemorrhoids. The white background indicated that this product was something positive, able to cope with hemorrhoids, lightweight, and easy to use (Gibraltar, 2012: 98-99).

Here is Figure 8:

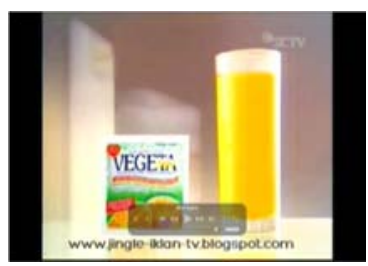

Figure 8.

Everyone knows that hemorrhoids traditionally can be prevented with consumption of natural fruits and vegetables. Though not expressly stated in these commercials, but the fourth social constructions (listed on page 101) formed a myth that this product was better than natural vegetables and fruits in prevention from hemorrhoids.

Furthermore, from the episode of Ulfa Dwiyanti version commercial, a conclusion can be drawn there are 4 constructions of sign, and one myth as a final product. The following is the brief elucidation (Gibraltar, 2012: 140141).

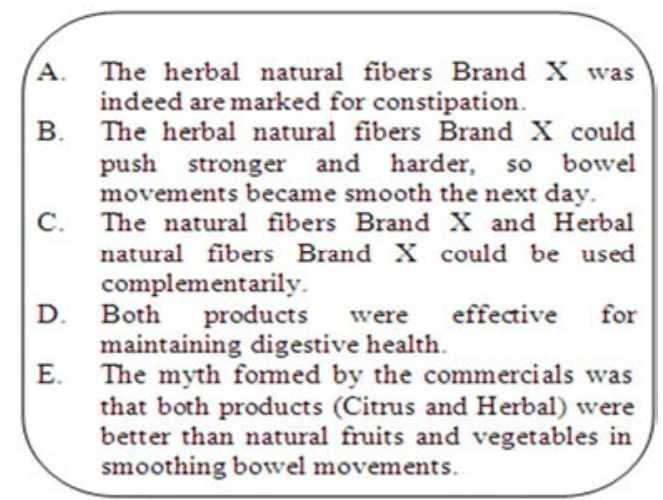

The first construction of sign (The herbal natural extract fibers Brand X was indeed earmarked for constipation) resided on Figures 1 to 3 . The brown blouse of Ulfa Dwiyanti showed how she was sad and unhappy due to digestive problem. Ulfa's hand gestures that held and pointed her abdomen showed that something was not right with her digestion, and she walked hastily. (Gibraltar, 2012: 108)

The background consisting of items put on white shelves suggested that the place had a positive characteristic, though it was unclear whether it was a storeor a pharmacy. Similarly, it was unclear whether the female interlocutor was a pharmacist or a shopkeeper. (Gibraltar, 2012: 107108)

The viewers' attention was focused to observe Ulfa Dwiyanti given that the camera motion was "dolly in". Ulfa said: "Ouch! I had no bowel movement for few days, I pile up garbage” (Gibraltar, 2012: 106-107).

This construction was reinforced by Figure 2. The most important of the scenewas the movement of the right hand (nonverbal) of the female interlocutor who held a sachet of herbal natural extract fibers Brand X and said: "There are now herbal natural extract fibers Brand X, especially ear marked for constipation". It suggested solution to the illness suffered by Ulfa Dwiyanti (Gibraltar, 2012: 111112).

The "close-up" camera motion on Figure 3 demonstrated not only intimacy, but rather directed the viewers' focus to observe the face of witty Ulfa Dwiyanti since it was combined with the "dolly-in" camera motion, signifying her understanding of what was explained by the female interlocutor by saying "Oоооо..." (Gibraltar, 2012: 114115).

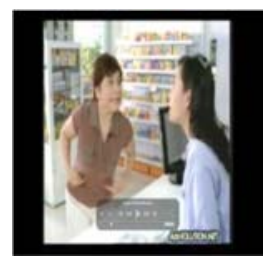

Figure 1. 


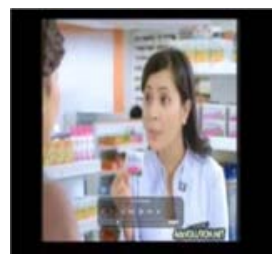

Figure 2.

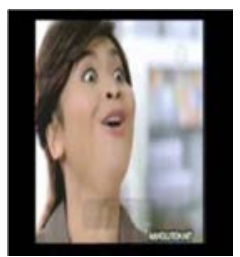

Figure 3.

The second construction of sign (The herbal natural extract fibers Brand X could push stronger and harder, so bowel movements became smooth the next day) was described by Figure 4. The left hand of the female interlocutor hold a sachet of herbal natural extract fibers Brand $\mathrm{X}$ and her right hand pushed the sachet (nonverbal) and said: "Herbal natural extract fibers Brand $X$ pushes stronger, bowel movements become smooth the next day". Meanwhile the other signs remained the same as those appeared on the first of construction sign (see page 12) (Gibraltar, 2012, 116-117).

Here is Figure 4:

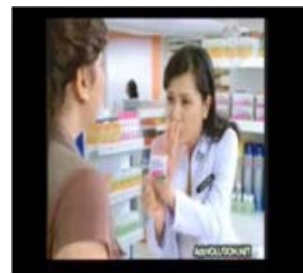

Figure 4.

The third construction of sign (The natural extract fibers Brand $X$ and Herbal natural extract fibers Brand X could be used complementarily) was actually already displayed on Figure 5. Ulfa Dwiyanti held the sachet and flipped it over (nonverbal), saying: "What's the difference with Citrusflavored natural extract fiber Brand X?" Her facial expression showed that she was very curious about something, and combination of close-up and dolly-in camera motions indicated how increasingly intimate Ulfa Dwiyanti was with the products while the eyes of viewers were focused on observing the scene. Meanwhile, other signs remained the same as before (Gibraltar, 2012: 120122).

Figure 6 strengthened the construction. The right hand held the herbal and the left held the citrus-flavored, while saying: "The Herbal natural extract fibers Brand $X$ is earmarked for constipation; after it is resolved, drink citrus-flavored natural extract fibers Brand X for routine bowel movements" (nonverbal). The medium-shot camera motion showed how personally familiar was the woman talking to Ulfa with both products, that she knew the ins and outs of the products (the personal closeness of human with the product) (Gibraltar, 2012: 123-127).

Then, Figure 7 further strengthened the construction. Ulfa Dwiyanti' spinning head movements, her witty facial expression, and her saying "It's really fabulous" seemed to strengthen the assumption of complementary relationship between both products (the verbal combined with the nonverbal). The close-up camera motion (Ulfa began to be intimate with the product) was combined with dolly-in camera motion in directing the viewers' eyes to Ulfa Dwiyanti (Gibraltar, 2012: 127-128).

Here are Figures 5, 6, and 7:

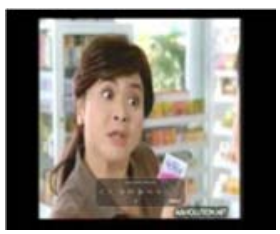

Figure 5.

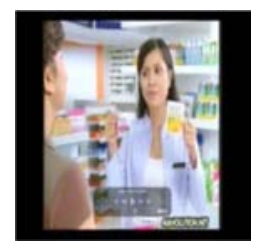

Figure 6.

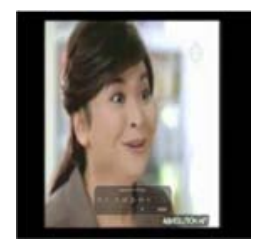

Figure 7.

The fourth construction of sign (Both products were effective for maintaining digestive health) was represented by Figure 9. Both sachets of the products were displayed simultaneously. The white background indicated that these productswere something positive, stimulating or helping bowel movements, lightweight (easy to use), and simple, honest and not containing ingredients harmful to health. The black color on the phrase "For Digestive Health" indicated that these products were good ones (a strong, firm structure) (Gibraltar, 2012: 134).

The fourth construction reinforced by Figure 10. Ulfa Dwiyanti was out of a room, wearing collared pink dress and white trousers. She moved her hipscomically while saying: "Thank God, I have no constipation again." Connotatively, this showed enjoyment and excitement due to being relieved from a problem with bowel movements (shown in a kinesiological manner by Ulfa's moving her hips, with a happy facial expression) (Gibraltar, 2012: 135).

Here are Figures 9 and 10: 


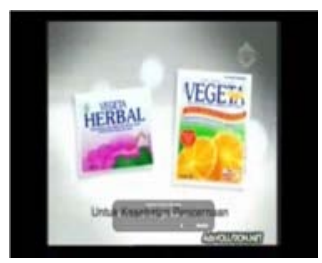

Figure 9.

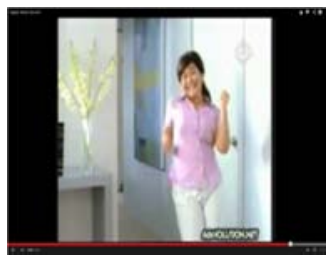

Figure 10.

Given that traditionally constipation can be resolved by the use of vegetables and fruits, the commercials involuntarily created a myth that both products were better than natural fruits and vegetables in smoothing bowel movements.

Thus, there were eight constructions of sign plus two myths in both natural extract fibers Brand X commercials. The four constructions of sign on the first commercial formed a myth that natural extract fibers Brand $\mathrm{X}$ was better than natural vegetables and fruits in the prevention from hemorrhoids. Then, the next four constructions of sign (second commercial) formed a myth that both products were better than natural fruits and vegetables in smoothing bowel movements. (Gibraltar, 2012: 203-204)

\subsection{Viewers' Interpretation of Both Myths}

In this second stage of the analysis, what was listed here has been through a good and thorough in-depth interview process, using a semi structured questions, in order to examine how the viewers interpretedboth commercials.

How did viewers interpret the myth? Or, more specifically, didviewers interpret it positively or negatively? The following is the explanation of both of these, starting from the myth formed in the first commercial, and then the second one.

Informant Wiwin (of lower-middle class) expressed her disbelief in the myth. Here is an excerpt of the interview with her:

"Indeed, the problem with bowel movements like this does happen frequently, and if it's not immediately resolved, it will cause adverse impacts. When I try natural extract fibers Brand $X$, it's true that subsequently my bowel movements become smoother, but it was also because I consume fruits as well. Additionally, after I heard that my friend wasn't able to defecate, I just don't believe in what I heard through the commercials" (Gibraltar, 2012: xv).

Wiwin added that her friends contrarily had difficulty defecating when taking this product. Here is the excerpt:

"I was so worry with her condition, but I personally believe more in natural laxatives. It's because another friend of mineremained having problem with defecation as smoothly as usual; instead, she had difficulty with defecation" (Gibraltar, 2012: xviii).

Informant Wiwin closed her remarks with the following:

"After I watched natural extract fibers Brand $X$ commercials, I don't fully believe in what is conveyed; before trying Brand X, I believe it, but after trying it. I do not believe it so much. So, I buy it as needed. If I had difficulty with bowel movements, I buy it at the moment, rather than on a daily basis" (Gibraltar, 2012: xxii).

In the same vein, Informant ADR (of lower-middle class) also wanted to try the product, but he still believed in vegetables and fruits as natural laxatives relative to the product. Here is an excerpt of the interview with her:

"Actually, I want try the product, but then I decided not try it since my parents said that eating papaya leaves was more efficacious. After all, it's more secure to consume papaya leaves since it is natural, not chemical. Additionally, my parents advised me to check whether or not the products have been registered in the Department of Health. The product itself is great" (Gibraltar, 2011: xxxviii).

Informant Rahma (of upper-middle class) was also not particularly paying attention to the myth formed by the commercials. Following is an excerptof the interview with her:

"I think the commercials are not so special to me, because in my daily life I do not pay attention to commercials. I just buy stuff as needed, not based on commercials" (Gibraltar, 2012: xlix).

Though not expressly opposing, informant FRM (of upper-middle class) also did not believe the myth so much. Here is an excerptfrom the interview with him:

"I guess that she had long suffered from these hard bowel movements, and then finally it is bloody. She lacks water and fibers in her food. It must also be coupled with fruits and vegetables" (Gibraltar, 2012: ixvii).

The most critical opinionwas unexpectedly expressed by informant SWD (an herbalist). He firmly criticized the commercials. Here is an excerpt of the interviews with him:

"The commercials create a very dramatic, torturing impression; it is as if before taking this product she was very tortured, but after taking this product, she is very happy. Well, that is called commercials. They promote that way, but I think it's not instant. Herbs obviously take time to be efficacious. Body needs processes to repair the damaged cells, which takes about three months" (Gibraltar, 2012: ixxxiv).

Likewise, informant SWD criticized the substances contained in the products. Here is the excerpt:

"I am still thinking of whether hemorrhoids can actually be resolved by taking this solution. We must be critical here. The solution ... what is the name? ... Plantago Ovata ...where it works in which parts of the body? Whether it works to smooth bowel peristalsis, or how, I think it is necessary that the manufacturer describes these issues" (Gibraltar, 2012: 1xxxiii).

To this point, a common thread can be drawn that the five informants, both of lower- and upper-middle classes and a herbalist did not believe in the myth that natural extract fibers Brand $\mathrm{X}$ was better than natural vegetables 
and fruits in preventing from hemorrhoids (on the first commercial). This could be demonstrated through in-depth interviews with those five informants.

With regard to Ulfa Dwiyanti version commercial, informant Wiwin responded critically to the myth to be formed. Here is an excerpt of the interview with her:

"I am quite critical to what is delivered by these commercials. It's because a friend of mine has taken the herbal natural extract fibers but her bowel movements has not become so smoothly; in fact, it has become increasingly worse, so I just don 't believe it" (Gibraltar, 2012: xxiv).

Nevertheless, informant Wiwin seemed to be influenced by Ulfa Dwiyanti on these commercials, which was then able to reduce her critical stance against the products. Here is an excerpt of the interview with her:

"Ulfa is comical and hilarious, Well, the presence of Ulfa makes I want to try this product. I think it's not contrived, but it's not for daily consumption; instead, it's only as needed. (Gibraltar, 2012: xxv).

Finally, informant Wiwin believed in the myth. Here is an excerpt of the interview with regard to this point:

"During in the store, I do not instantly buy citrusflavored natural extract fibers Brand $X$ and Herbal natural extract fibers Brand $X$ when I find them, but it depends on my bowel movements. When I have constipation, I buy them. But I do not buy them when I have smooth bowel movements (Gibraltar, 2012: xxv).

This was the case with informant ADR. He argued as follows:

"Well, the commercials want to suggest solutions that Herbal natural extract fibers and the other one are two different things. The herbalist for constipation, while the citrus-flavored is for routine and smooth defecation" (Gibraltar, 2012: xliv).

Informant ADR saw that the products were something great. Here is the excerpt of the interview with him with regard to this point:

"It means that the products are great; I think it's because these products are practical and drinkable anytime. They are herbal, which are also natural. After watching these commercials, I want to try them immediately, because I have already tried the citrus-flavored" (Gibraltar, 2012: xlv).

The response to the appearance of Ulfa Dwiyanti as the model of the commercials is as follows:

"Sounded funny and hilarious, and they make this ad interesting" (Gibraltar, 2012: xlv).

Both piece of information showed that informant ADR was indeed influenced by the myth launched by this commercial, in which both products can be used for laxatives. The third information indicated that informant ADR was interested in purchasing the products due to a boost from the appearance of Ulfa on those commercials.

The opposite is also expressed by informant Rahma. Following is the excerpt of the interview with her:

"Well, I become eager to try Herbal natural extract fibers Brand X because it could induce bowel movements, but it's only as needed"' (Gibraltar, 2012: Ixiii).

It means, Informant Rahma believed in the myth, albeit not in its entirely, and talked about Ulfa Dwiyanti as the comical figure. Here is an excerpt of the interview with her: Similarly, informant FRM rated this commercial positively. Here is an excerpt of the interview with him:

"It makes me at least interested in trying these products complementarily. At least, there is a solution to overcome constipation. Originally, I consume yoghurt, but then I tried the products. Moreover, just an advice, how if the product is made in the form of tablet, I think it will be more instant" (Gibraltar, 2012: ixxix).

It was only informant SWD, the herbalist doctor, who looked at the commercials negatively. Here is an excerpt of the interviews with informant SWD with regard to this point:

"The various drinks marketed to our society are all poisons, and can cause a person suffer from renal abnormalities if consuming them in quite a long period of time" (Gibraltar, 2012: ixxxviii).

Informant SWD reasonably argued so considering that his profession was an herbalist.

The common thread of the four of the five informants (of lower-middle and upper-middle classes) was that they believed in the myth constructed by the second commercial. However, someone who was "expert" in health (an herbalist) did not believe the myth. Further, the use of Ulfa Dwiyanti as the model on the commercial was in fact able to reduce viewers' negative interpretation of natural extract fibers Brand $\mathrm{X}$ and Herbal natural extract fibers Brand $X$, as well as stimulating the viewers to believe the myth, and consume the products.

The findings of the present study demonstrated the existence of the dynamics of viewers in interpreting the myth. There was a myth which was not easily believed by viewers (on the hemorrhoid version commercial), but there was a myth which was believed by viewers (on Ulfa Dwiyanti version commercial). The casting of the main model (Ulfa Dwiyanti) of the commercial also affected viewers' interpretation of the product advertised.

\section{Conclusion}

This paper is prepared to show the academic community that a semiotic study of any analysis unit (in this case natural extract fibers Brand $\mathrm{X}$ and Herbal natural extract fibers Brand X commercials) is not sufficient if it is only conducted on paper. There is a need for some breakthroughs that can make an analysis of commercial more comprehensive, which can be done by the incorporation of several theories and research methods. This paper attempted to address this issue.

This paper was motivated by the controversy of natural extract fibers Brand $\mathrm{X}$, which, on one side, received a number of awards in given years but, on the other hand, it was controversial since some parties considered it capable of harming consumers' health. In other words, there was contradictory information on these products.

This "contradictory information" led to the selection of two natural extract fibers Brand $\mathrm{X}$ commercials aired on televisions from 2009 to 2011, as the unit of analysis. Literature review indicated that the success of these 
products in the market was due to their unique advertising to the public by creating signs that led consumers to believe the products as "trusted" in overcoming the problem of digestive health.

Surely, there must be an "analytical tool" for the unit of analysis. At the first stage of the analysis, Roland Barthes'semiotics in this paper would be positioned as a "theoretical container" that held other thoughts, ranging from Arthur Asa Berger's concretization of signifier and signified, Barker's theory of colors and moods, Mark L. Knapp's nonverbalism, and Mas Dian \& Darmaprawira's theories of colors). In short, Roland Barthes'semiotics is a sociological thinking, which can also be used as a method of research to explore signs. According to Roland Barthes, semiotics is the sociology of signs, symbols, and representations. Certainly, it will produce a myth as the final product.

On the second stage of the analysis, signs would turn into symbols when it involved interpretation. This is the case with a myth, which is actually an accumulation of signs that turn intosymbols to be interpreted by viewers in a commercial. In this second stage, Susanne Langer'sdiscursive symbolism played an important role.

Methodologically, this study is an applied research, though it would have theoretical and methodological implications unusual to the realm of communications science. Usually, Roland Barthes'semiotics is positioned "merely" on the methodological level; instead, the present study indicated that this thinking could be raised or lowered to theoretical and methodological level depending on the unit analysis. In addition, this study attempted to combine two things in pairs: literature review with in-depth interviews, and illustrative method and negative sentence method in the data analysis stage. In reality, triangulation played a fairly important role in this study.

On natural extract fibers Brand $\mathrm{X}$ hemorrhoid version commercial, 4 constructions of sign were found: (1) Hemorrhoids were characterized by a bloody defecation; (2) Hemorrhoids, if not treated properly, may worsen, and lead to a tremendous pain; (3) Natural extract fibers Brand $\mathrm{X}$ can smooth bowel movement, and prevent users from hemorrhoids; (4) Natural extract fibers Brand X can make the digestive system healthy in a comprehensive manner. The myth emerged was that natural extract fibers Brand $\mathrm{X}$ was better than natural fruits and vegetables in preventing users from hemorrhoids.

Unfortunately, when this myth was tested to the public, none of them believed the myth. The public in this study includes those of lower-middle and upper-middle classes and an expert familiar with health issues.

Furthermore, 4 constructions of sign were found on Herbal natural extract fibers Brand X commercial: (1) the herbal natural extract fibers Brand $\mathrm{X}$ was indeed earmarked for constipation; (2) the herbal natural extract fibers Brand $\mathrm{X}$ could push stronger and harder, so bowel movements became smooth the next day; (3) the natural extract fibers Brand $X$ and Herbal natural extract fibers Brand X could be used complementarily; (4) both products were effective for maintaining digestive health. The myth formed by the commercial was that both products were better than natural fruits and vegetables in smoothing bowel movements.

Conversely, when this myth was tested to the public, there was dynamics due to the presence of Ulfa Dwiyanti as the model of this commercial. Four informants (of lowermiddle and upper-middle classes) believed the myth. Only one informant who was an "expert" in health problems did not believe the myth.

The finding showed how a celebrity was capable of changing or, at least, reducing viewers' negative or critical interpretation of a product advertised, particularly when the product was being hit by contradictory information in the society. The first commercial did not use celebrities, so that the myth formed was not trusted or interpreted negatively by the viewers. However, the second commercial used a celebrity and was able to reduce viewers' negative interpretation and disbelief through the funniness and comicality of the model of the commercial.

\section{References:}

[1] Adityawan, Arief. (2008). Propaganda Pemimpin Politik Orde Baru. Jakarta: LP3ES.

[2] Baxter, Leslie A \& Babbie. (2004) The Basics of Communication Research. California: WADSWORTH THOMSON LEARNING.

[3] Barthes, Roland. (2010). Membedah Mitos-Mitos Budaya Massa: Semiotika atau Sosiologi Tanda, Simbol, dan Representasi: Edisi Ketiga. Yogyakarta:Jalasutra.

[4] Broden, Thomas F. (2002). Image, Sign, Identity: Jean Marie Floch and Visual Semiotics. The American Journal of Semiotics 18. (From www.proquest.com )

[5] Darmaprawira, Sulasmi. (2002). Warna: Teori dan Kreativitas Penggunaannya. Jakarta: ITB Publishing.

[6] Dian, Mas. (2002). Pengaruh Warna dalam Feng Shui. Jakarta: PT. Elek Media Komputindo.

[7] Grow, Jean M. (2006). Stories of Community: The First Ten Years of Nike Women's Advertising. The Semiotic Society of America. (From www.proquest.com )

[8] Gibraltar, Muhamad. (2012). Interpretasi Pemirsa Terhadap Penanda dan Petanda (Analisis Semiotika Iklan Sari Serat Alami Merek X di Televisi Antara Tahun 2009-2011). Jakarta: Program Pascasarjana Ilmu Komunikasi Universitas Indonesia). Jakarta: Magister Ilmu Komunikasi. (Tesis)

[9] Griffin, E.M. (2006). A First Look At Communication Theory: Sixth Edition. Boston: Mc Graw Hill Inc.

[10] Harvey, Michael and Evans. (2001) Decoding Competitive Propositions: A Semiotic Alternative to Traditional Advertising Research. International Journal of Market Research. Vol. 43 Quarter 2, Second Quarter. (From www.proquest.com )

[11] Hirschman, Elizabeth C. (2003). Men, Dogs, Guns, And Cars: The Semiotic of Rugged Individualism. Journal of Advertising, Vol. 32 No.1 Spring (From www.proquest.com ). 
[12] Langer, Susanne. (1967). An Introduction to Symbolic Logic: Third Revised Edition. New York: Dover Publications Inc.

[13] Littlejohn, Stephen L. \& Foss. (2007). Theories of Communication: Seventh Edition. New Mexico: THOMSON.

[14] Pallupi, Dyah Hasto, Pambudi. (2005). Advertising That Sells: Strategi Sukses Membawa Merk Anda Menjadi Pemimpin Pasar. Jakarta: Gramedia.
[15] Seale, Clive, Gobo, Gubrium, and Silverman (2007). Qualitative Research Practice: Concise Paperback Edition. London: SAGE PUBLICATIONS.

[16] Sobur, Alex. (2009). Semiotika Komunikasi. Bandung: Rosdakarya.

[17] Tressider, Richard. (2010). Reading Food Marketing: The Semiotics of Marks \& Spencer. Dalam International Journal of Sociology and Social Policy. Vol. 30 No. 9 / 10, 2010. (From www.proquest.com) 